\title{
Cameriere's European formula for age estimation: A study on the children in Bosnia and Herzegovina
}

\author{
Latić-Dautović, Melina ${ }^{1}$; Nakaš, Enita ${ }^{2}$; Jelešković, Azra ${ }^{2}$; Cavrić, Jelena ${ }^{3}$; Galić, Ivan ${ }^{4}$ \\ 1 Dental Department, The Public Institution Health Centre of Sarajevo Canton, Bosnia and Herzegovina \\ 2 Department of Orthodontics, School of Dental Medicine, University of Sarajevo, Bosnia and Herzegovina \\ 3 Henry M. Goldman School of Dental Medicine Boston, University Boston, USA \\ 4 School of Medicine, University of Split, Croatia
}

\begin{abstract}
Introduction: A method for age estimation, based on measurements of projections of open apices and heights of developing permanent teeth on orthopantomograms (OPTs), was presented by Cameriere in 2006 and adopted European formula was presented in 2007. Aim: This cross-sectional study tested the accuracy of Cameriere's European formula on a sample from the City of Sarajevo, Bosnia and Herzegovina.

Materials and methods: A final sample of 560 OPTs of 305 girls and 255 boys aged 8 to 14 years was obtained. The sample was collected at the Department of Orthodontics, School of Dental Medicine at the University of Sarajevo (SFUNSA). Dental age was compared to chronological age and mean absolute error (MAE) was calculated. Intra-rater and inter-rater agreement of the evaluated variables were calculated.

Results: The dental age was underestimated when compared to chronological age, precisely, mean underestimation was -0.14 years in girls and -0.17 years in boys. The values of MAE were 0.62 years in girls and 0.56 years in boys. The greatest error was found for the 14-year old group; DA was -1.04 years and -0.70 years in girls and boys respectively.

Conclusion: Our results showed that Cameriere's European formula might be a useful tool for age estimation in children from Bosnia and Herzegovina under the age of 14 years.
\end{abstract}

Latić-Dautović M, Nakaš E, Jelešković A, Cavrić J, Galić I. Cameriere's European formula for age estimation: A study on the children in Bosnia and Herzegovina. South Eur J Orthod Dentofac Res. 2017;4(2):26-30.

Submitted: April 6, 2017; Revised: August 28, 2017; Published: October 15, 2017

\section{INTRODUCTION}

Teeth have been marked as a useful body system for age estimation in youth and elderly. ${ }^{1}$ In children and adolescents, there are different medico-legal and forensic questions, like the age of criminal responsibility or adult age, where dental age estimation can help to answer. ${ }^{2-6}$ According to the Study Group on Forensic Age Diagnostics (AGFAD; http://agfad.uni-muenster.de) ${ }^{2}$, the examination of different independent developmental systems including teeth is combined, to increase the accuracy of estimated age. ${ }^{7}$ For children and juveniles, the radiographs of hand-wrist and the teeth are the most reliable for assessing skeletal and dental

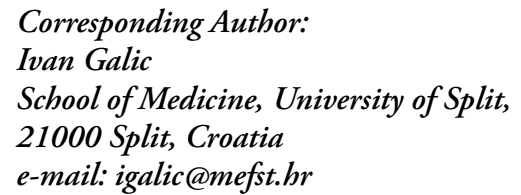

development. ${ }^{8-10}$ Developing permanent teeth in children are very useful for age estimation because of the possibility to study mineralization of all teeth on a single, panoramic X-ray (OPT). ${ }^{11}$ On the other hand, mineralization of teeth is not affected as is their eruption by external factors, such as crowding, retention or early extraction of deciduous teeth, on the other hand, social, economic or malnutrition status may affect skeletal growth. ${ }^{12-14}$ Most methods of age estimation in children evaluated mineralization of specific sets of teeth, most commonly mandibular. ${ }^{15}$ Historically, maxillary teeth were not appropriate for radiologic analysis because of inferior appearance to mandibular teeth and superposition with corresponding skeletal structures on analog X-rays which is now mostly improved and corrected in digital radiography. Distinct stages of mineralization were used to estimate dental mineralization, from the presence of a dental crypt and first calcification to the final closure of apices of the dental roots. ${ }^{16}$ Demirjian et al. ${ }^{16}$ introduced the 
most widely used approach for age estimation in children in 1973. Demirjian's method used seven teeth from one side of the mandible while full range mineralization of the teeth was divided into eight stages (A-H). Demirjian's approach, which used stages showed acceptable accuracy, especially after some methodological and statistical adaptation. ${ }^{17,18}$ Cameriere et al. ${ }^{19}$ demonstrated a different system of measuring the maturity of developing teeth. Instead of mineralization stages, Cameriere's method measure projections of open apices of developing teeth. ${ }^{19}$ Generally, in the Italian sample of 455 orthopantomogram (OPTs) it is proved that the chronological age is associated with the total sum of ratios of open apices and the length of tooth projection, the number of teeth with closed apex and gender. ${ }^{19}$ Furthermore, extended study on different European samples from Croatia, Germany, Kosovo, Italy, Slovenia, Spain, and the United Kingdom, totaling 2652 OPTs, has shown that variable countries of origin were not statistically significant for the regression formula, while gender, morphological variables second premolar, sum of normalized open apices (s), number of teeth with closed apices (N0), and the first-order interaction between $s$ and N0, contributed significantly to the fit, and were included in the linear regression model. ${ }^{20}$ Evaluation of Cameriere's formulas in a different population, including a study on BosnianHerzegovina samples, showed good accuracy for age estimation. This study aimed to test Cameriere's European formula on the sample of OPTs of children from Bosnia and Herzegovina.

\section{MATERIALS AND METHODS}

This cross-sectional study was carried out at the Department of Orthodontics, School of Dental Medicine at the University of Sarajevo (SFUNSA). A final randomly selected sample of 560 OPTs (305 girls and 255 boys), taken for different clinical indications during the period between January 2012 until July 2016, were analyzed. Inclusion criteria for OPTs were age between 8 and 14 years, a time when most of the children have an orthodontic examination for the first time, OPTs of high quality and presence of all permanent teeth. Exclusion criteria were no record of dental and skeletal anomalies, hypodontia of permanent teeth, age under 8 and over 14 years. All patients were clinically examined and analyzed at SFUNSA by the first author. Only specific variables of each patient were recorded for this study, including date of birth and OPT, gender and identification number, without the possibility to identify patients. All patients' parents or guardians previously signed an agreement and protocol with SFUNSA that clinically collected data and information from OPTs and other radiologic material that may be used for research without the possibility to identify the patient. The study was conducted by the ethical standards laid down in the Declaration of Helsinki (Finland) where the World Medical Association (WMA) developed the Declaration of Helsinki as a statement of ethical principles for medical research involving human subjects. ${ }^{21}$ Patients were divided into seven age groups according to real age. For example, the group of 10-years-olds includes all individuals of ages from 10.00 to
10.99. Table 1 shows the distribution of OPTs according to age groups and gender.

Table 1. Age and gender distribution of orthopantomograms from Bosnia and Herzegovina.

\begin{tabular}{lccc}
\hline Age (years) & Girls & Boys & Total \\
\hline $8-8.9$ & 38 & 32 & 70 \\
\hline $9-9.9$ & 44 & 40 & 84 \\
\hline $10-10.9$ & 38 & 40 & 78 \\
\hline $11-11.9$ & 32 & 30 & 62 \\
\hline $12-12.9$ & 55 & 32 & 87 \\
\hline $13-13.9$ & 55 & 39 & 94 \\
\hline $14-14.9$ & 43 & 42 & 85 \\
\hline Total & $\mathbf{3 0 5}$ & $\mathbf{2 5 5}$ & $\mathbf{5 6 0}$ \\
\hline
\end{tabular}

Cameriere's method was based on regression analysis of age as a dependent variable, and normalized measurements of open apices of the first seven mandibular teeth on the OPT, where gender (g) and number of teeth with finished maturation of root apex $\left(\mathrm{N}_{0}\right)$ are important dependent variables in calculating DA. ${ }^{19}$ All teeth without completed root maturation were analyzed, and the distance between the inner side of the open apices $\left(A_{i}, i=1, \ldots, 5\right)$ was measured. The sum of the distances between the inner sides of the two open apices was calculated for teeth with two roots $(A, i=6,7)$. Distances of open apices were normalized by dividing by the tooth length $\left(L_{i}, i=1, \ldots, 7\right)$ to minimize the effects of differences among $\mathrm{X}$-rays in magnification and angulation. ${ }^{3}$

Dental age was calculated according to the European formula:

Age $=8.387+0.282 \mathrm{~g}-1.692 \mathrm{x}_{5}+0.835 \times N_{0}-0.116 s-0.139 s \times N_{0}(1)$ where $\mathrm{g}$ is a variable, with $\mathrm{g}=1$ for boys and $\mathrm{g}=0$ for girls, $\mathrm{s}$ is the sum of the normalized widths of apices of the seven left permanent developing mandibular teeth $\left(x_{i}=A_{i} / L_{i}, i=1, \ldots, 7\right)$, and $x_{5}$ is the normalized measurement of the second premolar. ${ }^{20}$

Figure 1. An example of Cameriere's measurements of mandibular teeth, $x_{i}=$ $A / L_{i}, i=1 . \ldots .7$ of seven left mandibular teeth. $A_{i}, i=1 . \ldots .5$ (teeth with one root) is the distance between the inner sides of the open apex; $A_{i}, i=6$, 7 teeth with two roots) is the sum of the distances between the inner sides of the two open apices; and $L_{i}, i=1 \ldots . .7$ is the length of the tooth ${ }^{23}$.

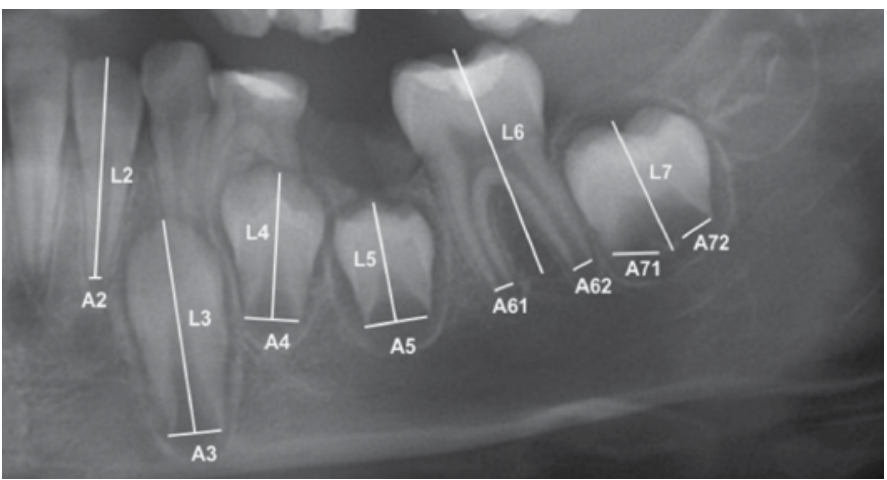




\section{Statistical analysis}

Repeatability and reproducibility of normalized widths of open apices or Intra-rater and inter-rater agreement between the same and the second observer were calculated by intra-class correlation coefficients. ${ }^{22}$ Cohen Kappa score (kappa) was used to calculate the intra- and inter-rater agreement of some teeth with a closed apex or $\mathrm{N}_{0}$. In total 60 randomly selected OPTs were examined two weeks after the final examination of OPT samples. The real age of each child was calculated as the difference between dental age according to Cameriere's European formula (DA) and chronological age (CA) or DA-CA. The Pearson correlation coefficient evaluated the relationship between DA and CA. Paired samples T-test was used to compare DA and CA, where positive values of DA-CA show an overestimation of dental age while negative values show underestimation. Mean absolute error (MAE) between DA and CA was used to quantify the accuracy of the method because DA-CA may overestimate or underestimate the dental age while MAE shows the error rate no matter if DA overestimates or underestimates CA. The mean absolute error or MAE was used to quantify the performance of $\mathrm{AD}$, the absolute values of the differences between CA $\left(\right.$ Age $\left._{i}, i=1, \ldots, n\right)$ and DA $\left(\right.$ Age $\left._{\text {est, }}, \mathrm{i}=1, \ldots, \mathrm{n}\right)$ :

$\mathrm{MAE}=\frac{1}{n} \sum_{i=1}^{n} E_{i}=\frac{1}{n} \sum_{i=1}^{n} \mid A g e_{C_{a m}, i}-$ Age $_{i} \mid$

where $\mathrm{n}$ is the number of subjects in the sample, and $\mathrm{E}_{\mathrm{i}},(\mathrm{i}=1$, $\ldots, n)$ is the absolute value of the ${ }^{i}$ th residual, or the difference between the DA and CA of the ith individual:
$\mathrm{DA}-\mathrm{CA}=\mathrm{Age}_{\mathrm{Cam}, i}-\mathrm{Age}_{i} \quad \mathrm{i}=1, \ldots, \mathrm{n}$

A positive value of DA-CA indicates overestimation while a negative value indicates underestimation of DA to CA. ${ }^{18}$ Kolmogorov-Smirnov test was used to test the normality of distribution of DA-CA, while Analysis of variance (ANOVA) was used to test if gender and age group as factors affect the variability of DA-CA.

\section{RESULTS}

Intra-class correlation coefficients for the same and a different observer were 0.949 (95\% CI, 0.916 to 0.969 ) and 0.923 (95\% CI, 0.874 to 0.953 ) which is in almost excellent agreement $(\mathrm{P}<0.001)$. Kappa for the same and a different observer was 1.00 . Pearson correlation coefficients were 0.925 and 0.936 for girls and boys respectively, which indicates a strong correlation between dental and chronological age. There was no statistically significant difference in real age between girls $(11.66 \pm 2.04$ years $)$ and boys (11.57 \pm 2.06$),(\mathrm{P}=0.597)$. The mean dental ages were $11.52 \pm 1.81$ years and $11.41 \pm 1.99$ years in girls and boys respectively. Cameriere's European formula underestimated dental age in both genders, Table 2. The greatest underestimation was for the last 14-years-old group. Figure 2 shows the distribution of DA-CA across age groups, boxplots show median and interquartile ranges, while whiskers are lines extending from the box to indicate the highest and lowest values, excluding outliers.

Table 2. A comparison of chronological age and dental age (years) calculated using Cameriere's European formula across different age groups in Bosnian-Herzegovian girls and boys.

\begin{tabular}{|c|c|c|c|c|c|c|c|c|c|c|c|}
\hline $\begin{array}{c}\text { Age } \\
\text { groups }\end{array}$ & $\mathbf{N}$ & Gender & $\mathrm{CA} \pm \mathrm{SD}$ & $\mathrm{DA} \pm \mathrm{SD}$ & $(\mathrm{DA}-\mathrm{CA}) \pm \mathrm{SD}$ & SEM & $\mathbf{L}$ & $\mathrm{U}$ & $\mathrm{MAE} \pm \mathrm{SD}^{\mathrm{b}}$ & $t(d f)$ & $\mathbf{P}^{\mathbf{a}}$ \\
\hline \multirow[t]{2}{*}{$8-8.9$} & 38 & Girls & $8.43 \pm 0.29$ & $8.79 \pm 0.64$ & $0.37 \pm 0.61$ & 0.10 & 0.17 & 0.57 & $0.54 \pm 0.46$ & $3.72(37)$ & 0.001 \\
\hline & & Boys & $8.49 \pm 0.29$ & $8.52 \pm 0.51$ & $0.03 \pm 0.50$ & 0.09 & -0.15 & 0.21 & $0.38 \pm 0.32$ & $0.33(31)$ & 0.740 \\
\hline \multirow[t]{2}{*}{$9-9.9$} & 44 & Girls & $9.51 \pm 0.29$ & $9.66 \pm 0.71$ & $0.15 \pm 0.62$ & 0.09 & -0.04 & 0.34 & $0.50 \pm 0.40$ & $1.60(43)$ & 0.117 \\
\hline & & Boys & $9.51 \pm 0.29$ & $9.47 \pm 0.60$ & $-0.04 \pm 0.61$ & 0.10 & -0.24 & 0.15 & $0.46 \pm 0.39$ & $-0.43(39)$ & 0.666 \\
\hline \multirow[t]{2}{*}{$10-10.9$} & 38 & Girls & $10.54 \pm 0.29$ & $10.46 \pm 0.54$ & $-0.08 \pm 0.50$ & 0.08 & -0.24 & 0.09 & $0.35 \pm 0.36$ & $-0.96(37)$ & 0.344 \\
\hline & & Boys & $10.48 \pm 0.31$ & $10.54 \pm 0.58$ & $0.07 \pm 0.60$ & 0.10 & -0.13 & 0.26 & $0.46 \pm 0.39$ & $0.69(39)$ & 0.497 \\
\hline \multirow[t]{2}{*}{$11-11.9$} & 32 & Girls & $11.40 \pm 0.30$ & $11.50 \pm 0.94$ & $0.10 \pm 0.90$ & 0.16 & -0.23 & 0.43 & $0.72 \pm 0.54$ & $0.62(31)$ & 0.537 \\
\hline & & Boys & $11.43 \pm 0.26$ & $11.10 \pm 0.65$ & $-0.33 \pm 0.68$ & 0.12 & -0.58 & -0.08 & $0.61 \pm 0.44$ & $-2.65(29)$ & 0.013 \\
\hline \multirow[t]{2}{*}{$12-12.9$} & 55 & Girls & $12.44 \pm 0.29$ & $12.35 \pm 0.91$ & $-0.09 \pm 0.83$ & 0.11 & -0.31 & 0.14 & $0.67 \pm 0.49$ & $-0.77(54)$ & 0.447 \\
\hline & & Boys & $12.56 \pm 0.30$ & $12.41 \pm 0.99$ & $-0.15 \pm 0.95$ & 0.17 & -0.50 & 0.19 & $0.81 \pm 0.51$ & $-0.91(31)$ & 0.368 \\
\hline \multirow[t]{2}{*}{$13-13.9$} & 55 & Girls & $13.48 \pm 0.29$ & $13.22 \pm 0.59$ & $-0.26 \pm 0.59$ & 0.08 & -0.42 & -0.10 & $0.54 \pm 0.35$ & $-3.27(54)$ & 0.002 \\
\hline & & Boys & $13.45 \pm 0.31$ & $13.50 \pm 0.71$ & $0.06 \pm 0.73$ & 0.12 & -0.18 & 0.29 & $0.54 \pm 0.49$ & $0.49(38)$ & 0.630 \\
\hline \multirow[t]{2}{*}{ 14-14.9 } & 43 & Girls & $14.59 \pm 0.27$ & $13.54 \pm 0.41$ & $-1.04 \pm 0.53$ & 0.08 & -1.21 & -0.88 & $1.05 \pm 0.53$ & $-12.97(42)$ & $<0.001$ \\
\hline & & Boys & $14.51 \pm 0.30$ & $13.81 \pm 0.58$ & $-0.70 \pm 0.65$ & 0.10 & -0.90 & -0.49 & $0.71 \pm 0.64$ & $-6.89(41)$ & $<0.001$ \\
\hline \multirow[t]{2}{*}{$8-14.9$} & 305 & Girls & $11.66 \pm 2.04$ & $11.52 \pm 1.81$ & $-0.14 \pm 0.78$ & 0.04 & -0.23 & -0.05 & $0.62 \pm 0.49$ & $-3.18(304)$ & 0.002 \\
\hline & 255 & Boys & $11.57 \pm 2.06$ & $11.41 \pm 1.99$ & $-0.17 \pm 0.73$ & 0.05 & -0.25 & -0.07 & $0.56 \pm 0.49$ & $-3.44(254)$ & 0.001 \\
\hline
\end{tabular}

Abbreviation: $C A$, chronological age; $D A$, dental age; SD, standard deviation; SEM, standard error of the mean; ${ }_{a}$ paired T-test between $D A$ and $C A ; D A-C A-$ difference between dental and chronological age; ${ }_{4} M A E$ - mean absolute error between dental and chronological age; $L$ - lower interval and $U$ - upper interval of $95 \%$ Confidence Interval of $D A-C A$; df, degrees of freedom. 
Table 3. Summary ANOVA table to test the difference in DA-CA for gender and age groups (dependent variable: $D A-C A$ ).

\begin{tabular}{cccccc}
\hline Source & $\begin{array}{c}\text { Type III Sum } \\
\text { of Squares }\end{array}$ & df & $\begin{array}{c}\text { Mean } \\
\text { Square }\end{array}$ & F-test & P \\
\hline Intercept & 1.129 & 1 & 1.129 & 2.399 & 0.122 \\
Gender & 0.444 & 2 & 0.222 & 0.472 & 0.624 \\
Age group & 60.061 & 6 & 10.010 & 21.270 & $<0.001$ \\
Error & 259.317 & 551 & 0.471 & & \\
\hline
\end{tabular}

In girls, dental age overestimates in 8, 9 and 11-year-olds, while in 10,12, 13 and 14-year-olds underestimates dental age. In boys, dental age overestimates in $8,10,12$ and 13-year-olds while in 9, 11 and in 14 years underestimates, Table 2 and Figure 2. Kolmogorov-Smirnov test for normality showed that DA-CA variables are normally distributed $(\mathrm{P}<0.200)$. ANOVA showed no statistically significant difference between girls and boys in DA-CA (Table 3), while Bonferroni post-test showed that there is a statistically significant difference between 14 -year-olds and all other age groups $(\mathrm{P}<0.05)$ and 13 -year-olds and eight-yearolds $(\mathrm{P}=0.030)$. The values of MAE varied between 0.35 years in 10 -year-olds to 1.05 years in 14-years-old girls and between 0.38 years in 8 -year olds to 0.81 in 12-year old boys, Table 2 .

\section{DISCUSSION}

In this study, we evaluated the Cameriere European formula on the sample OPTs of orthodontic patients from SFUNSA to verify the usefulness of the method in the children from the particular region in Bosnia and Herzegovina. Obtained results indicate that the European formula is useful for age estimation in the tested population. The greatest error or underestimation was found in the children of 14 years of age. Liversidge ${ }^{24}$ pointed out that at the age of 13 only a few children will not have finished maturation of the second molars and they are excluded from the testing sample. The proportion of the children with the unfinished maturation of the second molar visible on the OPT and available for measurement drastically decreases. ${ }^{25}$ Ambarkova et al. ${ }^{25}$ reported that first individuals with the complete maturation of the second molars were at the age of 12 years, while at the 13 years of age 27 of 32 (84\%) girls and 13 of 32 (41\%) boys have finished maturation of the second molar. Both the particular regression model and proportion of individuals with delayed maturation may contribute to the underestimation of dental age in the 14-years-old group. Further study should address this matter more extensively. Dental age was slightly underestimated in both genders. A cohort of the DA-CA across age groups showed that in the oldest age group error is the greatest and dental age underestimates by over a year in girls and over eight months in boys. If we would exclude the last 14-year olds group from our sample from the analysis, the mean values of DA-CA are $0.007 \pm 0.71$ years and $-0.05 \pm 0.69$ years and MAE of $0.55 \pm 0.44$ years and $0.53 \pm 0.44$ in girls and boys respectively. Cameriere's European formula was tested in different
Figure 2. Boxplots of the relationship between chronological age and difference between dental age according to Cameriere's European formula $(D A)$ and chronological age (CA) or (DA-CA).

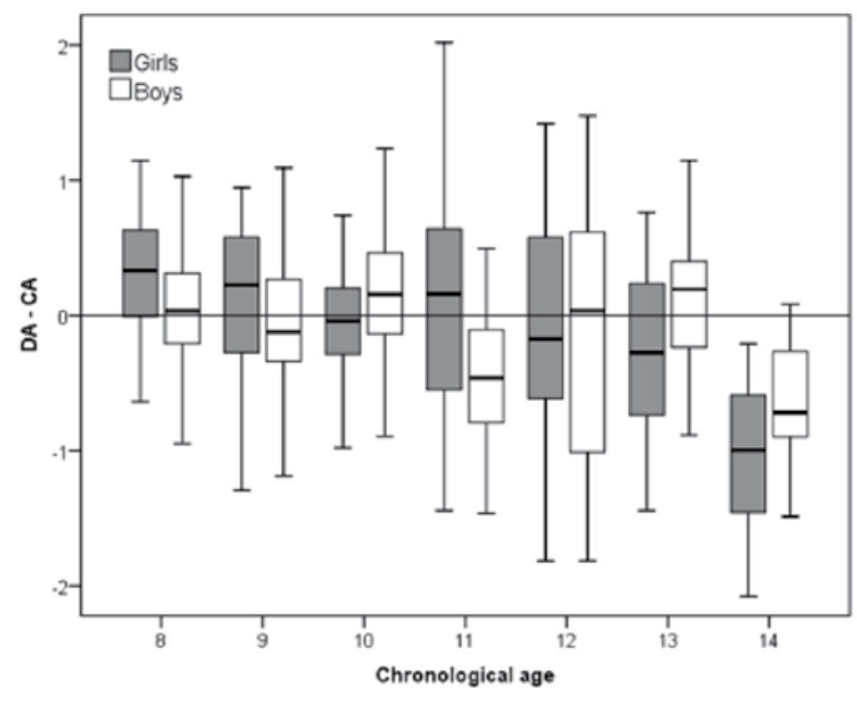

regions of the world. ${ }^{7,18,26-30}$ The European formula was compared to Willems and Haavikko methods on a sample of 1098 OPTs within age range between 6 and 13 years in the previous study from Bosnia and Herzegovina, DA overestimated for 0.09 years for girls (MAE, 0.53 years) and underestimated by -0.02 years for boys (MAE, 0.55 years), very close to our results of the same age range. ${ }^{18}$ Contrary to our study in which we analyzed digital OPTs from a single institution, Galić et al. ${ }^{18}$ used analog OPTs which were photographed by the digital camera. Galić et al. ${ }^{18}$ collected samples from different regions to represent a population within the entire country more definitively. Another study on the sample from Italy, Spain, and Croatia showed the median error of 0.081 years and 0.036 years while MAE was 0.48 years and 0.50 years in girls and boys, respectively. ${ }^{31}$ The most recent Colombian study by Rivera et al. ${ }^{32}$ also reported the substantial accuracy of the European formula; the mean underestimation was -0.25 years in girls (MAE, 0.57 years) and overestimation 0.08 years (MAE, 0.57 years).

Presented results indicate that Cameriere's European formula can be a useful tool dental age estimation in children from Bosnia and Herzegovina.

\section{CONCLUSION}

Our study showed the consistency in the accuracy of Cameriere's European formula on the sample from the Canton of Sarajevo. The results showed both good accuracy and reliability for estimation of dental age in children up to 14 years of age. Single regression formula showed a small difference in error, both DA$\mathrm{CA}$, and MAE. Since the study only had the available age range of a particular sample of orthodontic patients, further studies should evaluate the usefulness of the method in the younger children. 


\section{REFERENCES}

1. Schmeling A, Dettmeyer R, Rudolf E, Vieth V, Geserick G. Forensic Age Estimation. Deutsches Arzteblatt international. 2016;113(4):44-50.

2. Quispe Lizarbe RJ, Solís Adrianzén C, Quezada-Márquez MM, Galić I, Cameriere R. Demirjian's stages and Cameriere's third molar maturity index to estimate legal adult age in Peruvian population. Leg Med (Tokyo). 2017;25:59-65.

3. Lauc T, Nakas E, Latic-Dautovic M, Dzemidzic V, Tiro A, Rupic I, et al. Dental Age in Orthodontic Patients with Different Skeletal Patterns. Biomed Res Int. 2017;2017:8976284.

4. Balla SB, Galic I, P K, Vanin S, De Luca S, Cameriere R. Validation of third molar maturity index (I3M) for discrimination of juvenile/adult status in South Indian population. J Forensic Leg Med. 2017;49:2-7.

5. Djukic K, Zelic K, Milenkovic P, Nedeljkovic N, Djuric M. Dental age assessment validity of radiographic methods on Serbian children population. Forensic Sci Int. 2013;231(1-3):398.e1-5.

6. Zelic K, Galic I, Nedeljkovic N, Jakovljevic A, Milosevic O, Djuric $\mathrm{M}$, et al. Accuracy of Cameriere's third molar maturity index in assessing legal adulthood on Serbian population. Forensic Sci Int. 2016;259:127-32.

7. De Luca S, De Giorgio S, Butti AC, Biagi R, Cingolani M, Cameriere R. Age estimation in children by measurement of open apices in tooth roots: Study of a Mexican sample. Forensic Sci Int. 2012;221(1-3):155.e1-7.

8. Greulich WW, Pyle, Pyle SI. Radiographic Atlas of Skeletal Development of the Hand and Wrist. Second edition: pp. xvi. 256. Stanford University Press: Stanford; Oxford University Press: London; 1959.4º.p.256.

9. Schmidt S, Koch B, Schulz R, Reisinger W, Schmeling A. Comparative analysis of the applicability of the skeletal age determination methods of Greulich-Pyle and Thiemann-Nitz for forensic age estimation in living subjects. Int J Legal Med. 2007;121(4):293-6.

10. Cameriere R, De Luca S, Biagi R, Cingolani M, Farronato G, Ferrante L. Accuracy of three age estimation methods in children by measurements of developing teeth and carpals and epiphyses of the ulna and radius. J Forensic Sci. 2012;57(5):1263-70.

11. Galić I, Nakaš E, Prohić S, Selimović E, Obradović B, Petrovečki M. Dental age estimation among children aged 5-14 years using the Demirjian method in Bosnia-Herzegovina. Acta Stomatol Croat. 2010;44(1):17-25.

12. Cardoso HF. Epiphyseal union at the innominate and lower limb in a modern Portuguese skeletal sample, and age estimation in adolescent and young adult male and female skeletons. Am J Phys Anthropol. 2008;135(2):161-70.

13. Cameriere R, Flores-Mir C, Mauricio F, Ferrante L. Effects of nutrition on timing of mineralization in teeth in a Peruvian sample by the Cameriere and Demirjian methods. Ann Hum Biol. 2007;34(5):547-56.

14. Badrov J, Lauc T, Nakas E, Galic I. Dental Age and Tooth Development in Orthodontic Patients with Agenesis of Permanent Teeth. Biomed Res Int. 2017;2017:8683970.

15. Galic I, Vodanovic M, Jankovic S, Mihanovic F, Nakas E, Prohic S, et al. Dental age estimation on Bosnian-Herzegovinian children aged 6-14 years: evaluation of Chaillet's international maturity standards. J Forensic Leg Med. 2013;20(1):40-5.

16. Demirjian A, Goldstein H, Tanner JM. A new system of dental age assessment. Hum Biol. 1973;45(2):211-27.
17. Willems G, Van Olmen A, Spiessens B, Carels C. Dental age estimation in Belgian children: Demirjian's technique revisited. J Forensic Sci. 2001;46(4):893-5.

18. Galic I, Vodanovic M, Cameriere R, Nakas E, Galic E, Selimovic E, et al. Accuracy of Cameriere, Haavikko, and Willems radiographic methods on age estimation on Bosnian-Herzegovian children age groups 6-13. Int J Legal Med. 2011;125(2):315-21.

19. Cameriere R, Ferrante L, Cingolani M. Age estimation in children by measurement of open apices in teeth. Int J Legal Med. 2006;120(1):49-52.

20. Cameriere R, De Angelis D, Ferrante L, Scarpino F, Cingolani M. Age estimation in children by measurement of open apices in teeth: a European formula. Int J Legal Med. 2007;121(6):449-53.

21. World Medical Association. World medical association declaration of Helsinki: Ethical principles for medical research involving human subjects. JAMA. 2013;310(20):2191-4.

22. Ferrante L, Cameriere R. Statistical methods to assess the reliability of measurements in the procedures for forensic age estimation. Int J Legal Med. 2009;123(4):277-83.

23. Galic I, Pacifici A, Carbone D, Pacifici L, Jeroncic A, Cameriere R. Age estimation by the Cameriere's normalized measurements (CNM) of the single permanent mandibular tooth on a panoramic radiograph. Leg Med (Tokyo). 2017;26:65-72.

24. Liversidge HM. Dental age revisted. In: Irish JD, Nelson GC, editors. Technique and application in dental anthropology. Cambridge: Cambridge University Press; 2008. p. 234-52.

25. Ambarkova V, Galic I, Vodanovic M, Biocina-Lukenda D, Brkic H. Dental age estimation using Demirjian and Willems methods: cross sectional study on children from the Former Yugoslav Republic of Macedonia. Forensic Sci Int. 2014;234:187 e1-7.

26. Fernandes MM, Tinoco RL, de Braganca DP, de Lima SH, Francesquini Junior L, Daruge Junior E. Age estimation by measurements of developing teeth: accuracy of Cameriere's method on a Brazilian sample. J Forensic Sci. 2011;56(6):1616-9.

27. Balla SB, Venkat Baghirath P, Hari Vinay B, Vijay Kumar J, Babu DBG. Accuracy of methods of age estimation in predicting dental age of preadolescents in South Indian children. J Forensic Leg Med. 2016;43:21-5.

28. Guo YC, Yan CX, Lin XW, Zhou H, Li JP, Pan F, et al. Age estimation in northern Chinese children by measurement of open apices in tooth roots. Int J Legal Med. 2015;129(1):179-86.

29. Cugati N, Kumaresan R, Srinivasan B, Karthikeyan P. Dental age estimation of growing children by measurement of open apices: A Malaysian formula. J Forensic Dent Sci. 2015;7(3):227-31.

30. El-Bakary AA, Hammad SM, Mohammed F. Dental age estimation in Egyptian children, comparison between two methods. J Forensic Leg Med. 2010;17(7):363-7.

31. Cameriere R, Ferrante L, Liversidge HM, Prieto JL, Brkic H. Accuracy of age estimation in children using radiograph of developing teeth. Forensic Sci Int. 2008;176(2-3):173-7.

32. Rivera M, De Luca S, Aguilar L, Velandia Palacio LA, Galic I, Cameriere R. Measurement of open apices in tooth roots in Colombian children as a tool for human identification in asylum and criminal proceedings. J Forensic Leg Med. 2017;48:9-14. 